\title{
Reflection and Construction on Extracurricular Activities in College Mental Health Education
}

\author{
XUE Chunyan \\ Wuhan University of Science and Technology \\ Huazhong University of Science and Technology \\ Wuhan, China \\ E-mail: ivyxcy@163.com
}

\begin{abstract}
With the increasing emphasis on Chinese college students' mental health education, a variety of forms of extra-curricular activities are adopted. During the past few years, mental health education in extracurricular activities has achieved the significant results, but it still has some problems, such as over-administrative, inadequate funding and less-popularized. Mental Health Education extracurricular activities should build values of life care and spread peer group counseling activities to achieve its development goals. What's more, carrying out the "game-like" mental health education extracurricular activities is also a mean to enhance the student experience in mental health education activities, so that teachers and students have the chance to communicate .
\end{abstract}

Key words-Mental health education in extracurricular activities; current situation; reflection

\section{INTRODUCTION}

Mental Health Education refers to extra-curricular activities which organized outside the classroom with the aim to purposely cultivate college students' mental health. Mental health education in extracurricular activities has educational value to solve the special problems in the school personnel training that is to develop students' personality. This paper, on the basis of depth interviews on full-time teachers of Mental Health Education in Hubei Province, lists the initial success through constant innovation in the form of mental health education activities, explains the importance of role class construction, construction and other mental associations in Mental Health Education, put forward some problems which prevent the development of mental health education curriculum.

\section{CURRENT SITUATION OF MENTAL HEALTH EDUCATION AMONG COLLEGE STUDENTS IN EXTRACURRICULAR ACTIVITIES}

A. The Obvious Administrative Function in Carrying Out Extra-curricular Activities of Mental Health Education

Extracurricular activities are a favorable place to cultivate good psychological quality among students due to universality as well as flexibility. Currently, some universities are carried out mental health education in extracurricular activities. For example, the Mental Health Education in Chongqing's colleges has been routinized as well as institutionalized in various forms, 90 percent of schools Popularize mental health knowledge among their students. 64\% of colleges and universities in Yunnan Province organized mental health education extracurricular activities through a variety of ways. ${ }^{[2]}$ In 2008, 97 percent of colleges and universities of 33 colleges and universities in Xinjiang set up mental health education seminars, 85 percent of colleges and universities built Mental Health Association without enough professional guidance and training. ${ }^{[3]}$ In Hubei Province, the vast majority of colleges and universities have carried out extra-curricular activities on mental health education. One of the prominent features of these extracurricular activities in mental health education is the obvious executive power. The vast majority of mental health education institutions affiliated to Student Affairs Department or The School League Committee. The schools relationship between faculty departments and Student Affairs Department is a higher and lower level, so that the school departments of the faculty carry out an objective assessment of the Executive Order. The various educational institutions of mental health department have a clear mandatory to issue mental health education activities in the faculty and students. Several full-time mental health education teachers described the school mental health education activities situation: "Mental Health Education extracurricular activities should be adopted into year-end evaluation system of ideological and political education; faculty should not neglect the work." "The whole process for activity must be monitored and evaluated, and the evaluation will be included in the final score of the faculty's annual assessment of student work."

B. Extra-curricular Activities of the Mental Health Education Generally Organized by the Colleges or Universities

There are the following three main conditions to Organize extracurricular activities. First, extracurricular activities of mental health education uniformly carried out by the school to urge students' participation in the activities among faculties, such as Mental Health Education Month, Mental and Cultural Festival, Mental Health Day and other activities. The second is self-organized extra-curricular activities with rigid requirements for the participation of faculty and students from colleges, but with less requirement form facilities. The third one is some mental 
health education activities which spontaneously organized by college students' mental Health Association. The universities which take more than two or three forms of activities much more emphasized on mental health education, but only those which only adopted the third form of activity is less emphasis on college mental health education. According to interviews, it found that most colleges and universities take the first form of organization rather than to take the second or the third one.

\section{C. lack of mental health education funding}

The funding for extracurricular activities of mental health education is consistent with that of school mental health education. Those universities which have abundant funding generously sponsored the mental health education in various aspects. However, those universities without enough funding normally organized extracurricular activities for mental health education under restriction well as in clearly insufficient participation. The problems are that the current proportion of funding for mental health education is not high and the funding for mental health education is insufficient. Two full-time teachers from public colleges said that "the expense of mental health education, being disbursed from Student Affairs Department, is applied many times as well as insufficient sum.”

\section{REFLECTION ON CURRENT COLLEGE STUDENTS’ MENTAL HEALTH EDUCATION EXTRACURRICULAR ACTIVITIES}

A. Values on mental health education extracurricular activities: Maintaining universities' stability

Government clearly issued that mental health education is one part of the ideological and political education category. Some scholars have pointed out that the Mental Health Education should return back to the field of ideological and political education, in order to achieve the Mental Health Education for sustainable development. ${ }^{[4]}$ In carrying on extracurricular activities, specific mental health education $t$ seems to be included in the field of ideological and political education, aiming to maintain the current stability. ${ }^{[5]}$ Although Health Mental Education aimed at maintaining universities' stabilities, its specialty hasn't received enough attention. In sight of the ideological and political education, extra-curricular activities of Mental Health Education marked a strong ideological and political education brand. As an ideological and political education task for maintaining stability of school mission, all students must participate in various mental health education activities organized by the school.
B. Prevention and Adaption to the Extra-curricular Activities as the Main Target of Mental Health Education

Based on active objects, mental health education in extracurricular activities highlights its adaptability objectives. Freshmen are usually as the main active object in extra-curricular activities of Mental Health Education. After entering college, freshman faces self-care, self-management, active learning, and ideological self-education, self-selection and other targets on university adjustment problems, so that numbers of universities organized mental health education extracurricular acclivities with different themes to help freshmen adapt to new college life as the main objective. Due to inadequate funding for Mental Health Education, only can extracurricular activities take into account its short-term goals that target at prevention and adaptability. Maintaining school stability is the values of current extracurricular activities for Mental Health Education . CHENG Jiafu said that mental health education is an important means of promoting universities' stability as well as the basic purpose. ${ }^{[6]}$ Coping with students' potential mental problems is only the short-term goals of mental health education, so that mental health education activities can not be planned as a whole or complete as development goals. What's worse, extracurricular activities for mental health education are less concerning about the "explore the meaning of life" or other related topics.

C. Mental Health Education in Extra-curricular Activities as the Main Content to Knowledge Transfer

In the research on relevant literature and in-depth interviews among teachers, this paper suggested that universities should organized a wide range of extra-curricular activities in mental health education to achieve practical objectives, such as mental health knowledge propaganda, psychological health education seminars, and class meetings. With obvious signs of "teaching" in current mental health education activities in universities, mental health education and mental health teaching have less obvious differences. The teaching method of mental health education is theory based, "empty talk" or "rational analysis", thus resulting in cultivating "knowledge" and neglecting "cognitive" characteristics. Seminar-centered extracurricular activities are likely to cultivate active participants in the "knowledge" but not an open, generative educational process. Over-emphasizing knowledge in extracurricular activities leads to ignore the core needs of life, thus unable to focus on the differences and changes among individuals. 


\section{CONCLUSION}

A. Establishing the Values of Life Care in Extra-curricular Activities of Mental Health Education

Extracurricular activities are an indispensable and greatly superior to develop students' ability in practical activity. In the continuous development of the special needs, students should participate in varied and adequate activities to get better growth and development in physical and mental ability. Through continuous testing in extracurricular activities, they are able to show and prove their activity, constantly improve their mobility or explore self, self-development, so that their personality has been continuously improved and developed. Furthermore, In order to better realize the value of mental health education, college mental health education curriculum should foster values of life care. This paper suggests that universities should expand the form of extra-curricular activities to achieve awareness and action, cognition and experience linkage among college students in mental health education. Students gained internalized knowledge through experience, thus to achieve informed complementary blend as well as to reflect the unique charm in extracurricular activities of mental health education. According to different grades or groups of students, Universities should organize different themes to carry out extra-curricular activities.

B. Reinforcing Life Experience by implementing the "Game-like" Extracurricular Activities of Mental Health Education

Games played an irreplaceable role in characteristic formation and hobbies development so that "game-like" extracurricular activities had a significant impact on mental health education. Most people considered that the game is more appropriate for school-age children but not meaningful for college students' mental health education. In the current extracurricular activities of Mental Health Education, not only did extensive use of these games have implications for psychotherapy actors, but also had significance with the development. Freud believed that the game is an effective means to stimulate aspirations and comfort children in traumatic events. Eriksson said that the game is a kind of acting or performance to display one's anxiety and expectation in order to promote the development of college students' emotional stability and maturity. To achieve the best effect of psychological treatment in activities, group counseling activities must be led by professional teachers. On the one hand, the professional teachers helped the participants to get maximize happiness, enjoyment and satisfaction in the application of the games. On the other hand, professional teachers required to understand and respect the ideas from the group members, thus automatically repairing the psychological energy to achieve treatment. In the game, College students have a strong motivation to learn boring theoretical mental health knowledge by various games. At the same time, students are able to get a rich life experience in a particular situation experience of extra-curricular activities in mental health education.

\section{ACKNOWLEDGEMENT}

Fund Source: This article is phased research achievements of Hubei Province in 2015 Humanities and Social Sciences Department of Education project "Effect of positive psychology, group counseling on improving college students' mental health problems.”

\section{REFERENCES}

[1] WANG Lin, Research on The current situation of mental health service system in Chongqing university [D] Southwest University Library: Master's degree thesis, 2008: 36

[2] Teacher Training on Mental Health Education and Research Center in Yunnan, Mental Health Education Survey Report in Yunnan [C] .2009: 4.http: //www.doc88.com/p-889680586822.html (2014-8 -5)

[3]HE Jianzhong, Research on Situation and Countermeasures of College Students' Psychological Health Education in Xinjiang [J] Xinjiang Education Institute, 2010, (12): 78-84

[4] ZHANG Weiping, the mental health study on higher education [M] Shenyang: Liaoning University Press, 2013: 9-15

[5] WANG Xiyao, On the target of ideological and political education [J] Huazhong Agricultural University (Social Sciences), 2006, (2): 20-23 